\title{
Revista Brasileira de Enfermagem REBEn \\ Temas éticos e bioéticos que inquietaram a Enfermagem: publicações da REBEn de 1970-2000
}

REVISÃO

\author{
Ethical and bioethical issues disturbing nursing: REBEn's publications from 1970 to \\ 2000 \\ Cuestiones éticas y bioéticas que inquietan la enfermería: publicaciones de la \\ REBEn de 1970 a el 2000
}

\section{Maria Madalena de Andrade Santiago}

Doutora em Enfermagem. Mestre em Filosofia. Professor Adjunto da Área de Pesquisa do Departamento de Enfermagem da Universidade Estadual do Rio de Janeiro, RJ.

\section{Marisa Palácios}

Doutora em Ciências. Mestre em Saúde Coletiva. Professora Adjunto da Faculdade de Medicina e Núcleo de Estudos em Saúde Coletiva da Universidade Federal do Rio de Janeiro, $R J$.
Submissão: 26/10/2005

Aprovação: 11/03/2006

\section{RESUMO}

Estudou-se temas éticos e/ou bioéticos publicados na Revista Brasileira de Enfermagem - REBEn, que inquietaram a Enfermagem no período 1970 - 2000, objetivando identificar nos artigos publicados, temas relacionados à ética/bioética e discutir as perspectivas teóricas nas quais os autores fundamentam suas argumentações. $O$ desenho do estudo é de tipo documental ou bibliográfico. Os resultados mostraram que nos últimos 30 anos houve aumento gradativo, no número de artigos que debatem questionamentos éticos. Os principais temas relacionados à Bioética foram: dilemas e conflitos éticos associados a assistência à saúde, Deontologia, formação ética do enfermeiro e ética em pesquisa. Após 1984 surge o primeiro estudo, versando sobre tema usual da bioética e o termo bioética aparece pela primeira vez em 1998.

Descritores:Enfermagem; Ética; Bioética

\section{ABSTRACT}

It was studied the ethical and/or bioethical issues published in the Revista Brasileira de Enfermagem (Brazilian Nursing Journal - REBEn) that disturbed the nursing in the period between 1970 and 2000. The aim was to identify in articles published in the REBEn, during the mentioned period, subjects related to the ethics/bioethics. To discuss the theoretical perspectives in which the authors base their arguments. The study was quantitative and qualitative, documentary or bibliographical type. Results: in the last 30 years it had gradual increase in the number of the articles that debates ethical questionings. After 1984 appear the first study, with bioethics connotation, in which the author discourses on the interventions of nursing before the patient in imminent death, with the purpose to verify the relations between the personal and professional values of the nurse. Was Valeria Lunardi who used the bioethics term for the first time in 1998.

Descriptors: Ethics; Bioethics; Nursing.

\section{RESUMEN}

Fueran estudiados los temas éticos y/o bioéticos publicados en la Revista Brasileña de Enfermería (REBEn) que inquietaran la enfermería en el período entre 1970 y 2000. Objectivando: Identificar en los artículos publicados en la REBEn, durante el período mencionado, los temas relacionados con la ética/bioética. Discutir las perspectivas teóricas en las cuales los autores basan sus discusiones. El estudio era cuantitativo y cualitativo, tipo documental o bibliográfico. Resultados: en los 30 años pasados tenía aumento gradual en el número de los artículos que debatían los cuestionamientos éticos. Después de 1984 aparezcó el primer estudio, con connotación bioética, en la cual el autor discurre sobre las intervenciones de la enfermería delante del paciente en muerte inminente, con el propósito de verificar las relaciones entre los valores personales y profesionales del enfermero. El término bioética fue utilizado por la primera vez por Valéria Lunardi en 1998.

Descriptores: Ética. Bioética. Enfermería.

Santiago MMA, Palácios M. Temas éticos e bioéticos que inquietaram a Enfermagem: publicações da REBEn de 1970-2000. Rev Bras Enferm 2006 maio-jun; 59(3):349-53.

\section{CONSIDERAÇÕES INICIAIS}

O presente trabalho tem como objetivo geral identificar os temas éticos / bioéticos que inquietaram os enfermeiros nos últimos trinta anos. Entre os motivos para a escolha deste assunto destaca-se o fato deste tema ser ainda hoje, pouco abordado na área de enfermagem, embora os conflitos éticos provoquem debates acalorados em diferentes situações. Constantemente, com a finalidade de prestar um serviço de melhor qualidade e que, na medida do possível, promova justiça social somos levados a refletir sobre nossa prática cotidiana e reavaliar os princípios éticos que a fundamentam. Outro aspecto que despertou o interesse foi a presunção de possível lacuna no conhecimento. 
Ainda que as divergências éticas no setor saúde não se constituam em novidade, supõe-se que a implantação da Resolução 196/96 do CNS/MS e a conseqüente criação dos Comitês de Ética em Pesquisa (CEP) tenham estimulado o interesse pelo assunto. Portanto, faz-se necessário a preparação de profissionais que inspirados nos paradigmas bioéticos vigentes sejam capazes de propor uma perspectiva bioética em consonância com a realidade sócio-cultural brasileira.

A bioética discute do ponto de vista da ética, as relações entre os avanços no campo do conhecimento científico e tecnológico e o cotidiano da vida em sociedade. Surgida nos Estados Unidos da América na década de 70, a perspectiva introduzida pela bioética e hoje disseminada por todos os continentes, se distanciou da conotação da moral religiosa e respeita a pluralidade de tendências ${ }^{(1)}$.

A inclusão do conteúdo de bioética, no campo da formação do enfermeiro, resultou da alteração ocorrida em 1994, a partir da Portaria $n^{0} .1712$ de 15 de dezembro de 1994 do MEC, que estabeleceu novas diretrizes curriculares para o currículo de graduação em enfermagem, posteriormente, a Portaria 1518 de 14 de junho de 2000 integrou os conteúdos de bioética ao ensino da ética ${ }^{(2)}$ que passou a denominar a disciplina "Exercício de Enfermagem - Deontologia, Ética Profissional e Legislação", abrangendo os conteúdos de ética, bioética e fundamentos legais do exercício profissional de enfermagem. Esta inclusão resultou de proposições encaminhadas por Instituições de Ensino Superior e pela Associação Brasileira de Enfermagem (ABEn) ao Departamento de Políticas do Ensino Superior SESu / MEC, que por sua vez, encaminhou à Comissão de Especialistas do Ensino de Enfermagem, também do MEC, uma proposta de integração dos conteúdos de Bioética ao ensino da Ética.

A proposta sugere a preocupação da categoria com o tema. Portanto, há que se sensibilizar o debate acerca dos referenciais teóricos que norteiam as diferentes perspectivas. Pois, situações de conflito exigem a tomada de decisões fundamentadas em posturas éticas, refletidas criticamente ou não.

Estas reflexões levaram-nos a questionar que vertentes teóricas emergem dos artigos publicados, nos últimos trinta anos, na principal $e$ mais tradicional revista de enfermagem, a Revista Brasileira de Enfermagem (REBEn) da Associação Brasileira de Enfermagem.

Com 0 intuito de nortear este estudo, elaboramos as seguintes questões "quanto foi publicado sobre ética / bioética em enfermagem a partir da década de 70?", "quais os principais temas abordados pelos autores?", "em que perspectiva ética / bioética os autores se fundamentam?". E para respondê-las construímos os objetivos: a) identificar os artigos publicados na Revista Brasileira de Enfermagem (REBEn), no período de 1970 a 2000, que contém temas relacionados à ética / bioética, b) identificar os principais temas abordados e por fim, discutir as perspectivas teóricas nas quais os autores fundamentam suas argumentações.

$O$ debate bioético deve ser constante particularmente, entre os profissionais de saúde, porque o avanço científico e tecnológico nos surpreende com novidades, que exigem solução, onde o fator racional deve prevalecer sobre o emocional, ou que as decisões advenham de padrões de comportamento socialmente previstos e aceitos, porém oriundos dos valores culturais.

\section{REFERENCIAL TEÓRICO}

Relembrando a história, no início dos tempos civilizados não existia uma ética direcionada às ciências humanas ou às da vida. As normas gerais é que ditavam o comportamento social humano, e como a ética está relacionada à vida, estas se confundiam com a ética médica.

A evolução dos conceitos de ética se deu através dos tempos, permitindo a identificação de alguns marcos conceituais e históricos que caracterizam diferentes momentos da ética geral e sua evolução para uma ética direcionada para as ciências médicas e enfim, para a bioética.

Em sua origem no Brasil as discussões éticas, no campo da enfermagem, têm se pautado numa postura que pode ser caracterizada como conservadora por privilegiar aspectos como a religiosidade, autoritarismo, obediência, hierarquia, subserviência e outras ${ }^{(2)}$.

Primordialmente, o ensino de ética se ocupava quase que exclusivamente em tratar dos direitos e deveres profissionais. Esta tendência, de certa forma, permaneceu até a publicação, em 1994, da portaria anteriormente referida.

Concordamos que os códigos de deontologia são bem-vindos quando incorporam normas morais defensáveis, mas em alguns casos, pela simplificação exagerada das exigências morais podem mascarar a compreensão dos profissionais, levando-os a supor que apenas 0 cumprimento de todas as regras do código será suficiente para os eximirem de suas obrigações morais. Eventualmente, os códigos parecem se opor às regras morais mais gerais ou que estão em condição superior a elas, podendo sugerir nestes casos, maior proteção aos interesses profissionais que introduzir uma perspectiva moral imparcial e abrangente ${ }^{(3)}$. Daí, a relevância do aprofundamento do tema.

\section{Por que várias correntes?}

Hume filósofo do século XVIII foi quem primeiro afirmou que a moral é baseada em sentimentos e não em razão, baseado na idéia de que sempre haverá um princípio para o qual não haverá razão. Mais tarde, já no séc XX, Maclntyre afirma que a racionalidade só tem sentido dentro de uma tradição histórica. Não há como pensar em razões num sentido universal. "Qual racionalidade?", "justiça de quem?", são questões pertinentes informando a existência de comunidades que diferem grandemente em termos morais. Embora esses filósofos tenham utilizado esses argumentos para negar a possibilidade de uma ética universal, Rachels ${ }^{(4)}$ os recupera para afirmar a possibilidade de ser construída uma ética universal - descobrir que argumentos fazem sentido para pessoas racionais em geral e não para um conjunto limitado de pessoas. Ao lado de questões como essa no campo teórico, das teorias éticas, a Bioética se constitui como disciplina que pretende aproximar a Ética como uma área de produção de conhecimento da filosofia com o campo de produção de saberes e práticas que intervêm na vida dos seres e do planeta. Essa aproximação é fruto de uma articulação dialética que produz novos e crescentes desafios tanto para a produção filosófica quanto para as ciências da vida e suas interações com a sociedade. A Bioética se constitui assim, como um campo disciplinar capaz de, com suas reflexões, produzir modelos teórico metodológicos para auxiliar a tomada de decisão ética no campo da saúde. Assim, só para citar os mais significativos, apresentaremos, em rápidas palavras as abordagens baseada em princípios, a utilitarista e a da ética do cuidado.

Sob o título de abordagem baseada em princípios é reunida uma grande variedade de abordagens. $O$ que as caracteriza é ter no mínimo algumas normas morais centrais no julgamento. Normas morais (princípios e regras) são diretrizes gerais para a ação que especificam que determinadas ações são proibidas, requeridas ou permitidas em determinadas circunstâncias. Princípios são as diretrizes mais gerais e as regras são mais específicas. No Principialismo de Beauchamps e Childress os principais princípios são os da beneficência, da não maleficência, da autonomia e da justiça. 0 método de utilização dos princípios repudia a aplicação direta por dedução dos princípios às situações concretas. Os quatro princípios são obrigações prima-facie, não são mera recomendação. É preciso atribuir pesos a regras e princípios quando são contraditórios em uma dada situação concreta, e assim construir muito bons argumentos para infringir um princípio, que na situação concreta esteja em desvantagem ${ }^{(5)}$.

$\mathrm{Na}$ abordagem utilitarista, o que faz uma ação ser correta ou errada 
são suas conseqüências ${ }^{(6)}$. A conseqüência mais importante é o aumento ou diminuição da quantidade de bem-estar de todos os afetados pela ação. Nesse sentido, a melhor ação é a que produz o máximo de bemestar. A noção de bem-estar está relacionada a obtenção de alto grau ou grau razoável de qualidade de vida que no todo a pessoa almeja ou prefere ter. Incluem-se todos os seres sencientes como objeto de preocupação moral. Em resumo, a abordagem utilitarista propõe agir de forma a garantir o maior bem-estar para o maior número de pessoas.

Ética do cuidado ${ }^{(7)}$ é uma forma de compreensão do agir ético e está baseada em 5 idéias centrais: Atenção moral, Compreensão com simpatia, Consciência das relações, Acomodação Resposta. A voz do cuidado compreende que os agentes estão envolvidos em contextos sociais particulares, relações e narrativas pessoais, que dirigem suas atenções morais a outros reais e estão abertas a compreender com simpatia e identificar-se com esses outros.

A ética do cuidado pressupõe relações humanas no interior das equipes de saúde respeitando as especificidades técnicas de cada profissional e colocando as questões morais para reflexão de forma aberta e igualitária, condições indispensáveis para que se possa construir consensos nas situações concretas onde os dilemas morais acontecem.

\section{MÉTODO}

Para a realização desta pesquisa optou-se por desenvolver uma investigação documental ou bibliográfica, a fim de observar a evolução dos temas publicados acerca do assunto. Iniciamos a pesquisa a partir do surgimento do termo bioética com Van Resselaer Potter ${ }^{(8)}$, na década de 70. Partindo do pressuposto que antes de 19700 interesse dos pesquisadores estaria voltado para temas relacionados ao Exercício Profissional e os debates envolvessem a elaboração do Código de Ética e Deontologia dos Profissionais de Enfermagem. A fixação do recorte final em 2000 deve-se a compreensão que transcorridos seis anos da publicação da portaria do MEC, seria suficiente para a absorção das informações e, conseqüentemente, para que a reflexão sobre estas questões pudesse ser assimilada, debatida e divulgada.

Uma das razões para a escolha de fontes documentais para a realização do estudo está no fato dos dados permitirem o acesso a um conhecimento objetivo da realidade e a deteç̧ão de "mudanças nas atitudes e valores sociais" ${ }^{\prime 9}$. A pesquisa bibliográfica permite conhecer as contribuições culturais ou científicas do passado, aproximando o pesquisador do que foi escrito, dito ou filmado no passado sobre determinado assunto. A pesquisa bibliográfica não é mera repetição do que já foi dito ou escrito sobre certo assunto. Mas, propicia o exame de um tema sob novo enfoque ou abordagem, chegando a conclusões inovadoras ${ }^{(10)}$. Ao fazer uma re-leitura 0 que foi produzido pode-se visualizar aspectos que de outra forma passariam despercebidos, como pontos obscuros ou lacunas do conhecimento. Além de ser um reforço paralelo no referencial teórico e na análise de sua própria pesquisa ${ }^{(10)}$.

A escolha metodológica permitiu a análise de informações objetivas referentes a identificação das revistas e artigos e, informações subjetivas relativas aos significados dos temas aí contidos. A decisão de examinar apenas as publicações da REBEn, embora existam outras revistas com qualificação melhor deve-se que é o periódico nacional de enfermagem de publicação regular mais antigo, julga-se, ser esta revista, um dos mais respeitados e reconhecidos entre os profissionais da área de enfermagem, além de ser qualificada na avaliação do Qualis ${ }^{a}$ da CAPES

\footnotetext{
a Qualis - É o processo de classificação de periódicos, anais, jornais e revistas versão 1.0 utilizado por programas de pós-graduação para a divulgação da produção intelectual de seus docentes e alunos, que enquadrada as publicações em categorias indicativas de qualidade $A, B$ ou $\mathrm{C}$ e do âmbito de circulação, que pode ser local, nacional ou internacional. Este processo adotado pela CAPES visa atender as necessidades especificas do sistema de avaliação. A classificação é feita ou coordenada pelo representante de cada área e passa por processo anual de atualização.
}

como C Internacional.

A dificuldade de se encontrar todas as publicações em um mesmo acervo ou disponíveis em veículo eletrônico nos levou a coletar as informações em diferentes bibliotecas localizadas no município do Rio de Janeiro, esta foi uma tarefa árdua, visto que o estado de conservação e a organização dos periódicos são precários.

O critério para inclusão dos artigos foram as palavras-chave: deontologia, código, legislação, exercício profissional, prática social, direitos dos pacientes, responsabilidade, morte, paciente terminal, transplante, aborto, humanização e cidadania. A coleta das informações ocorreu no final de 2004.

Para seleção dos artigos leu-se primeiramente os títulos contidos nos sumários das revistas, depois os resumos dos artigos, a fim de verificar se ambos continham a mesma informação. A seguir, criou-se uma ficha contendo ano, número e mês de todas as revistas, a página inicial da publicação, o título, o nome autor e o resumo, o que permitiu a análise minuciosa dos textos. À medida que analisávamos as revistas estas eram separadas das demais, o que garantia o controle.

Dentre as dificuldades para a seleção dos resumos destacamos: haver artigos que debatiam questões éticas, cujas palavras-chaves não apareciam nos títulos. Alguns títulos não traduzirem exatamente 0 conteúdo dos resumos, assim, em alguns casos leu-se o artigo na integra. Esta pré-análise foi fundamental para a compreensão dos aspectos abordados pelo autor e para ratificar a seleção, que poderia ser mascarada caso ocorresse somente a partir do título contido no sumário.

A análise do conteúdo dos artigos fundamentou-se no modelo de análise temática de Bardin ${ }^{(11)}$. Neste modelo as unidades de registro se constituem em palavras-chaves, frases ou parágrafos e permitem a visualização dos temas mais significativos em cada texto ou artigo, assegurando maior confiabilidade aos resultados da análise ${ }^{(11)}$. No primeiro momento, procedeu-se a leitura flutuante, a seguir, uma leitura mais profunda a fim de identificar as palavras mais significativas do resumo. Finalmente, as palavras foram contabilizadas e, avaliada sua relevância. As informações subjetivas foram agrupadas por semelhanças ou estranhamentos e organizadas em categorias temáticas. Após a contabilização, as palavras-chaves foram dispostas por afinidade dando origem a quatro categorias. Apresenta-se a seguir os resultados da análise dos dados objetivos e das informações subjetivas.

\section{RESULTADOS}

No período de 1970 - 2000 foram publicados 132, editados 106 números da REBEn e selecionados 44. Porém, examinados só 33 cujos resumos abordavam o tema, descartando-se 11 que consistiam em relatórios ou divulgação de legislação.

$\mathrm{Na}$ década de 70 foram publicados 47 números. Nas 38 revistas impressas, havia 08 textos, que embora divulgassem questões éticas não foram analisados por que: quatro consistem em documentários relativos aos Congressos Brasileiros de Enfermagem (sendo um relativo do XXIV CBEn realizado em Belo Horizonte - MG, e três relativos do XXVIII CBEn), três contêm Códigos (o Código de Ética do Conselho Internacional de Enfermeiras; o Código de Deontologia de Enfermagem aprovado pela Resolução COFEN - 9, de 04/10/1975; e o Código de Ética da Associação Brasileira de Enfermagem - 1975) e um apresenta o Relatório da Comissão Especial do Código de Ética da Associação Brasileira de Enfermagem.

$\mathrm{Na}$ década de 80 observa-se que dos 40 números publicados, efetivamente foram editadas 29 revistas. Sendo selecionados 10 textos e analisados 08 artigos. Tal como na década anterior, entre as publicações escolhidas um era o Código da Enfermeira - conceitos éticos aplicados à enfermeira do Conselho Internacional de Enfermeiras e o 
outro a "nova" Lei do Exercício Profissional da enfermagem: uma análise crítica, ambos sem resumos.

Houve nesta década uma redução no número de publicação, que de seis passou a quatro números anuais. Ainda assim, o número de revistas editadas foi menor que o previsto, levando-nos a supor que a crise econômica que neste período atingiu o país, tenha também atingido à editoração da REBEn.

Nos anos 90 constata-se a publicação de 40 e, edição de 34 números da revista. Dos 21 textos selecionados foram analisados 20 artigos, um não tinha resumo, o que confirma 0 aumento no número de artigos sobre o tema. Presume-se que esta elevação seja conseqüência da superação da crise econômica já comentada e que o aumento expressivo de artigos publicados sobre o tema, cerca de $50 \%$, resulte da publicação da Resolução 196/96.

A publicação e a edição, de cinco exemplares da REBEn em 2000, sugere a superação da crise. Neste ano foram selecionados e analisados cinco textos. 0 aumento publicações sobre o tema já evidenciado na década anterior se mantém.

O exame das revistas editadas neste período demonstra aumento progressivo do número de artigos sobre o tema, a cada década, embora em 2000, tenha sido analisado apenas um ano, esta tendência é melhor visualizada no Tabela a seguir.

Tabela 1. Evolução do número de artigos que abordam temas da Bioética e número de revistas publicadas: REBEn 1970-2000.

\begin{tabular}{lcc}
\hline Décadas & Revistas Publicadas & Artigos Publicados \\
\hline 1970 & 38 & - \\
1980 & 29 & 8 \\
1980 & 34 & 20 \\
2000 & 5 & 5 \\
\hline Total & 106 & 33 \\
\hline
\end{tabular}

\subsection{Análise dos resumos}

Das informações qualitativas contidas nos artigos emergiram quatro categorias, a saber: Categoria 1 - dilemas e conflitos éticos associados a assistência à saúde, Subcategoria 1.1 - assistência, Subcategoria 1.2 reflexões Categoria 2 - Deontologia, Categoria 3 - formação ética do enfermeiro, e Categoria 4 - ética em pesquisa.

Categoria 1 - assistência à saúde, contempla temas relacionados à assistência de enfermagem propriamente dita e reflexões teóricas sobre a prática. Deste modo, seu conteúdo foi dividido em duas (02) subcategorias.

Subcategoria 1.1 - assistência e/ou ações de enfermagem, engloba pacientes terminais ou morte, direitos dos pacientes, doação de órgãos e implicações éticas da assistência. Esta subcategoria contém trechos sobre "identificar as intervenções de enfermagem frente ao paciente em morte eminente" (R-1), "as implicações éticas na assistência ao paciente crítico em (...) eutanásia, doação de órgãos para transplante" (R-5), "discute o enfrentamento de situações de conflito ético, presentes no cotidiano de enfermagem" (R-23). Outro recorte revela o que o autor destaca na ação do profissional junto à família "Ao trabalharmos com a família precisamos levar em consideração o que a mesma pensa a respeito de suas funções, pois isto vai direcionar e/ou definir o papel que ela desempenha no seu cuidado" (R-25).

Percebe-se nos fragmentos que os autores abordam questões da bioética. Entretanto, não fundamentam seus argumentos, nem fazem referência às teorias mais reconhecidas, embora alguns de textos sejam recentes. Acredita-se que no Brasil, o ensino de ética na enfermagem se assemelhe ao da medicina, restringindo-se ao estudo da deontologia ou aos Códigos de Ética ${ }^{(11)}$.

Subcategoria 1.2 - reflexões teóricas sobre a prática social, definição de responsabilidade e/ou comparação entre valores pessoais e profissionais. Os recortes revelam as inquietações éticas dos enfermeiros, como o que: "define o termo responsabilidade no sentido geral" (R-3), outro em que 0 autor diz: "(...) consiste em uma reflexão teórica acerca da participação social" (R-19). E outro acerca das "questões que envolvem a situação de vida e morte" (R-10).

Ainda que em nosso país o ensino de ética careça de estudos sobre as relações entre a ética e educação / formação profissional(11). Nota-se que entre os enfermeiros existe interesse pelo tema, e ao refletirem sobre sua prática provavelmente, surgirão novas respostas às suas inquietações.

Categoria 2 - deontologia - refere-se a textos sobre: a "regulamentação e controle do exercício profissional dos enfermeiros" (R-21), "responsabilidade civil, penal e ética do enfermeiro à luz da legislação vigente" (R-32), outro "comenta Código de Ética dos Profissionais de Enfermagem" (R-6), "compara as legislações de 16 países da América Latina"(R-16) e ainda "analisa os Códigos de Ética de 1958, 1975 e 1993"(R-18).

A análise revela que os autores iniciaram o debate de questões éticas a partir da apresentação, comparação, comentários e crítica aos códigos de ética profissional. Os códigos de ética constituem um importante debate no interior da Bioética tanto no que diz respeito a seu efeito, ou seja a seu papel na regulação da conduta dos profissionais quanto no conteúdo, ou 0 que deve mudar ao se refletir as questões mais abrangentes. Tais questões referem-se tanto aos temas do avanço das biotecnologias e seus impactos sobre os seres sencientes e o ambiente, quanto da revisitação às teorias éticas em suas aplicações a área da saúde. Isto confirma que particularmente na enfermagem e na medicina os códigos estimularam as reflexões e o debate sobre problemas de ética biomédico ${ }^{(3)}$. Porém, evidencia-se a incorporação de uma visão mais crítica e reflexiva na abordagem da ética, deslocando o foco para além da perspectiva da deontologia exclusivamente ${ }^{(12)}$.

Categoria 3 - formação profissional - esta categoria engloba: ensino, cursos, currículos. Os fragmentos nos mostram preocupação quando: “(...) apresenta alguns dados históricos do ensino da ética (...) e situa a disciplina Exercício de Enfermagem" (R-4), "compreender o primeiro contato que os estudantes (...) tem com a morte na sala de anatomia" (R-29), e "constatar (...) as concepções de (...) cidadania, compromisso social (...)" (R-27),

Nota-se que os autores abordam aspectos históricos do ensino da ética, do exercício profissional e outros. Compreendendo que 0 agir e a prática do enfermeiro se concretizam na ação exercida sobre aquele que necessita, ou requer sua presença, proporcionando conforto e bem estar físico, mental e social e, portanto, deve contemplar a pessoa de forma integral|(13). Constata-se que os responsáveis pela formação preocupamse em assegurar conteúdos não só científicos e tecnológicos, mas também relativos à conduta profissional, como certamente ocorre nas demais áreas da saúde, os conteúdos de ética frequentemente são repassados por meio de outras matérias consideradas disciplinas "preferenciais"(12).

Categoria 4 - pesquisa - este recorte compreende os comitês de ética em pesquisa, no qual o autor visa "apresentar as Resoluções nacionais que normatizam a área de pesquisa em seres humanos" e "provocar a reflexão sobre a necessidade de controle" e "orientar sobre a criação de comitê"(R-26).

Ainda que sobre este tema existisse apenas um artigo, julgamos relevante apresentá-lo, porque antes da Resolução cabia ao pesquisador aplicar sua própria ética na pesquisa. E neste sentido, a Res. 196/96 concretiza a institucionalização do controle ético. Por outro lado, demonstra o interesse dos editores em estimular a formação de opinião e não apenas divulgar informações aos assinantes.

\section{CONSIDERAÇÕES FINAIS}

Pode-se afirmar que os objetivos foram atingidos, embora não se tenha discutido as perspectivas teóricas nas quais os autores fundamentam 
suas argumentações, porque estas não emergiram dos textos.

Constata-se 0 aumento gradativo no número de artigos que debatem questionamentos éticos, nos últimos 30 anos, com maior concentração na década de 90 , totalizando 44 artigos publicados. Até o inicio dos anos 80 as publicações tinham o propósito de apresentar os códigos de ética ou mesmo compará-los.

Após 1984 surge o primeiro estudo, com conotação bioética, neste trabalho 0 autor discorre sobre as intervenções de enfermagem frente ao paciente em morte iminente, com a finalidade de verificar as relações entre os valores pessoais e profissionais do enfermeiro.

O termo bioética, contudo, só viria a ser empregado em 1998, por Valéria Lunardi no título de seu artigo "Bioética aplicada à assistência de enfermagem" - onde "discute o enfrentamento de situações de conflito ético, presentes no cotidiano da enfermagem".

Dentre os temas discutidos sobressai a temática assistencial com abordagens sobre as ações de enfermagem relativas a pacientes terminais ou morte, direitos dos pacientes, doação de órgãos, implicações éticas e significativos textos onde os autores fazem reflexões teóricas sobre a prática social, definição de responsabilidade e/ou comparação entre valores pessoais e profissionais.

A seguir destaca-se a deontologia com textos sobre: legislação, exercício profissional. Outro tema debatido pelos pesquisadores foi a formação profissional, com aspectos históricos do ensino da ética e do exercício profissional. Salienta-se finalmente, o texto sobre o Comitê de Ética em Pesquisa, visto que o artigo ressalta a importância da reflexão sobre a necessidade de controle em pesquisa, neste sentido, a Res. 196/96 concretiza a institucionalização do controle ético e ainda pretende, orientar os leitores sobre a criação dos Comitês.

Um aspecto já assinalado na seção Método, diz respeito à conservação do material bibliográfico. Não pretendemos aqui julgar os responsáveis por tal situação, apenas consideramos importante divulgar que este acervo documental que guarda a história do cuidado da profissão de enfermagem, uma preciosidade para nós, e não totalmente armazenado em meio eletrônico, está sendo destruído. A conservação deste material deve ser desejada para seu compartilhamento quer com profissionais da área de saúde ou com os demais membros da sociedade.

Esta evidência nos leva a presumir que os usuários das bibliotecas talvez se esqueçam que estas guardam tesouros do conhecimento inestimáveis, acumulados durante anos a fio. Por outro lado, imagina-se, quem usa este acervo têm algum interesse pelo saber ali guardado. Pois, os materiais ali preservado, quer seja, livro, periódico científico ou documentos não são facilmente encontrados em outros locais.

No entanto, constatou-se que "misteriosamente" inúmeros artigos, e por vezes, o número inteiro de um periódico simplesmente "desapareceu" da biblioteca, situação esta nos suscitou outros questionamentos. Como e porque isto ocorre? A quem cabe a responsabilidade pela preservação deste acervo? Que valor damos à memória da profissão? Que valores transmitimos aos novos profissionais? Neste momento, deixamos esta reflexão em aberto, pois, não é nossa intenção investigar tal problema. Contudo, consideramos inadmissivel omitir tal fato.

\section{REFERÊNCIAS}

1. Fortes PAC, Zoboli ELCP. Bioética e Saúde Pública: entre o individual e o coletivo. In: Fortes PAC, Zoboli ELCP, organizadores. Bioética e Saúde Pública. São Paulo (SP): Loyola; 2003. p.11-24.

2. Figueiredo $\mathrm{AM}$. Da ética à prática pedagógica: a busca do significado do ensino da ética na enfermagem. (dissertação). São Gonçalo (RJ): Universidade Salgado de Oliveira; 2001.

3. Beauchamp TL, Childpress JF. Princípios de ética biomédica. Tradução de Luciana Pudenzi. São Paulo (SP): Editora Loyola; 2002.

4. Rachels J. Ethical theory and bioethics. In: Kuhse H, Singer P, editors A Companion to Bioethics. Oxford (UK): Blackwell Publishers; 1998.

5. Childpress J. A principle based approach. In: Kuhse $H$, Singer $P$, editors. A Companion to Bioethics. Oxford (UK): Blackwell Publishers; 1998.

6. Hare RM. A utilitarian approach. In: Kuhse $H$, Singer $P$, editors. A Companion to Bioethics. Oxford (UK): Blackwell Publishers; 1998.
7. Manning R. A care approach. In: Kuhse $H$, Singer $P$, editors. A Companion to Bioethics. Oxford (UK): Blackwell Publishers, 1998.

8. Sgreccia E. A bioética e o novo milênio. Tradução de Antonio Pedrini. Bauru (SP): EDUSC; 2000.

9. Gil AC. Métodos e técnicas de pesquisa social. São Paulo (SP): Atlas; 1999

10. Lakatos EM, Marconi MA. Fundamentos de Metodologia Científica. 3a ed. São Paulo (SP): Atlas; 1995.

11. Bardin L. Análise de conteúdo. Lisboa (POR): Edições 70; 1979.

12. Rego S. A formação ética dos médicos: saindo da adolescência com a vida (dos outros) nas mãos. Rio de Janeiro (RJ): FIOCRUZ; 2003.

13. Santiago MMA. $O$ saber acadêmico de enfermagem: constituição e representações em três programas de pós-graduação (tese). Rio de Janeiro (RJ): Escola de Enfermagem Anna Nery, Universidade Federal do Rio de Janeiro; 2000. 